\title{
A cross-sectional survey of relationship between serum TSH level and blood pressure
}

\author{
D Liu ${ }^{1}$, F Jiang ${ }^{1}$, Z Shan, B Wang, J Wang, Y Lai, Y Chen, M Li, H Liu, C Li, H Xue, N Li, \\ J Yu, L Shi, X Bai, X Hou, L Zhu, L Lu, S Wang, Q Xing and W Teng \\ Department of Endocrinology and Metabolism and the Institute of Endocrinology of the First Affiliated \\ Hospital, China Medical University, Shenyang, China
}

It is still controversial whether subclinical hypothyroidism and euthyroidism affect blood pressure. The study aimed to explore the relationship between different levels of thyroid-stimulating hormone (TSH) and blood pressure in the participants with subclinical hypothyroidism and euthyroidism. A total of 1319 participants were administered a questionnaire survey, and their blood pressure, height and body weight measurements were taken. Blood samples were taken to test serum TSH. FT3 and FT4 were further examined if TSH was abnormal. Participants were divided into euthyroid group and subclinical hypothyroidism group. Euthyroid group was further divided into three groups: group $A$ (TSH 0.3-0.99 $\mathrm{mIU} \mathrm{I}^{-1}$ ), group B (TSH 1.0-1.9 $\mathrm{mIU} \mathrm{I}^{-1}$ ) and group C (TSH 1.91-4.8 $\mathrm{mlUI}^{-1}$ ). Results showed that different levels of serum TSH had no relation with systolic blood pressure (SBP) and diastolic blood pressure (DBP). The prevalence of hypertension in subclinical hypothyroidism group was significantly

Keywords: TSH; subclinical hypothyroidism; blood pressure higher than euthyroid group in females (41.3 vs $25.6 \%$, $P<0.05)$. The risk of hypertension in subclinical hypothyroidism group was significantly higher than that in the euthyroid group after adjusted for age, gender, smoking status, HOMA-IR (homoeostasis model assessment of insulin resistance) and body mass index (odds ratio $(\mathrm{OR})=1.753,95 \%$ confidence interval $(\mathrm{Cl})$ 1.0672.879, $P=0.027)$. This association was stronger in females (OR $=3.545,95 \% \mathrm{Cl} 1.576-7.975, P=0.004)$, but there was no statistical significance in males. Within normal range of TSH, both SBP and DBP were similar among the three groups. The prevalence and risk of hypertension were also similar among the three groups. In conclusion, the prevalence of hypertension in subclinical hypothyroidism group was significantly higher than in euthyroid group in females. Change of TSH in normal range did not affect blood pressure.

Journal of Human Hypertension (2010) 24, 134-138; doi:10.1038/jhh.2009.44; published online 25 June 2009

\section{Introduction}

Thyroid dysfunction, both hypo- and hyperthyroidism, may increase the risk of hypertension. ${ }^{1,2}$ However, it is still controversial whether mild thyroid dysfunction, such as subclinical hypothyroidism and also euthyroidism, affect blood pressure. Previous studies have found that hypertension had existed in the patients with subclinical hypothyroidism who are characterized as having high serum thyroid-stimulating hormone (TSH) level and normal thyroid hormones. ${ }^{3}$ Subclinical hypothyroidism was an independent risk factor for atherosclerosis and myocardial infarction in elderly women. ${ }^{4}$

Correspondence: Professor Z Shan, Department of Endocrinology and Metabolism and Institute of Endocrinology, The First Affiliated Hospital of China Medical University, No. 155 Nanjing Bei Street, Heping District, Shenyang, Liaoning 110001, PR China. E-mail: shanzhongyan@hotmail.com

${ }^{1}$ These authors contributed equally to this work.

Received 14 January 2009; revised 4 April 2009; accepted 20 April 2009; published online 25 June 2009
Recently, some researches ${ }^{5-8}$ had investigated cross-sectionally the relation between thyroid function and blood pressure. Some found that there was a modest, but significant positive association between serum TSH and blood pressure within the normal serum TSH range, ${ }^{5,6}$ but the Framingham Heart Study investigators reported no correlation between serum TSH and any of the thyroid hormone levels in euthyroid participants. ${ }^{8}$ This epidemiological study explored the relation between different levels of serum TSH and blood pressure in the participants with subclinical hypothyroidism and euthyroidism on the basis of cross-sectional epidemiological survey.

\section{Patients and methods}

Participants

In 2007, a total of 1534 inhabitants, aged 18-85 years, of three communities in DaDong district, 
Shenyang city, participated in a stratified sample survey on thyroid diseases and type 2 diabetes.

Exclusion criteria were (i) participants having a personal history of thyroid disease or taking medication affecting thyroid function, such as thyroxine, antithyroid drugs, glucocorticoid, antiepileptic and contraceptive drugs etc.; (ii) pregnant women or within the first year of postpartum period; (iii) participants without important relevant information; (iv) participants with diabetes, and treated with oral hypoglycaemic drugs or with insulin; (v) participants who were recently diagnosed with hypothyroidism or hyperthyroidism in this investigation; (vi) participants with hypertension who had taken oral antihypertensive drugs in the past 4 weeks. Moreover, 14 participants with subclinical hyperthyroidism were also excluded from the study. Finally, 1319 participants were enrolled and evaluated.

\section{Methods}

1. The questionnaire: The questionnaire included general information, such as name, gender, ethnicity, date of birth, address, identification card number, educational qualification, profession, family income, telephone number, duration of time living in DaDong district, history of childbearing, status of medical insurance, involvement in sports and their diet intake (including state of iodine intake), history of smoking and drinking, family history and personal history of thyroid disorders and other diseases.

2. Measurement of blood pressure, height and body weight: All the participants were made to rest for at least $30 \mathrm{~min}$ and then blood pressure of their right arm was measured twice with a desk-model sphygmomanometer with the participants in a sitting position. There was a 3-min interval between the two measurements for each participant, and then the mean value of the two measurements was used. Height and body weight were measured to calculate body mass index (BMI). BMI = body weight $(\mathrm{kg}) /$ height $\left(\mathrm{m}^{2}\right)$.

3. Blood sample collection: Fasting blood samples were drawn for serum TSH, fasting plasma glucose and insulin tests. Serum FT3 and FT4 were further examined if TSH was abnormal. The Homoeostasis model assessment of insulin resistance (HOMA-IR) was calculated using the following formula: HOMA-IR = fasting plasma glucose $\left(\mathrm{mmol} \mathrm{l}^{-1}\right) \times$ insulin $\left(\mathrm{mIU} \mathrm{l}^{-1}\right) / 22.5$.

4. Assay: Serum TSH, FT3 and FT4 were tested with super-sensitive chemiluminescence immunoassay (IMMULITE, Diagnostic Products Corporation, Los Angeles, CA, USA), plasma glucose was tested with hexokinase law (the first Japanese pharmaceutical kit, Kyoto, Japan), and insulin with radioimmunoassay (Biotechnology Research Institute of the North Port, Beijing, China). The intra-assay coefficients of variation were $<8 \%$ and the inter-assay coefficients of variation were $<10 \%$. The reference ranges of TSH, FT4 and FT3 were $0.3-4.8 \mathrm{mIU} \mathrm{l}^{-1}, 10.3-24.5$ and 2.3$6.3 \mathrm{pmol}^{-1}$, respectively.

5. Diagnostic Criteria: (1) Hypertension: $S B P \geqslant$ $140 \mathrm{~mm} \mathrm{Hg}$ and/or $\mathrm{DBP} \geqslant 90 \mathrm{~mm} \mathrm{Hg}$ under quiescent condition, or with previous history of hypertension. (2) Hyperthyroidism: TSH $<0.3 \mathrm{mIUl}^{-1}$, FT3 $>6.3$ and/or FT4 $>24.5 \mathrm{pmoll}^{-1}$. Subclinical hyperthyroidism: TSH $<0.3 \mathrm{mIUl}^{-1}$, FT3 and FT4 within the reference range. (3) Hypothyroidism: $\mathrm{TSH}>4.8 \mathrm{mIUl}^{-1}$, FT4 $<10.3 \mathrm{pmol} \mathrm{l}^{-1}$. Subclinical hypothyroidism: $\mathrm{TSH}>4.8 \mathrm{mIU} \mathrm{l}^{-1}$, FT4 within the reference range.

\section{Statistical analyses}

Data processing and statistical analysis were performed by SPSS 11.5 software. $\chi^{2}$-test was used for the analysis of counting data. The $t$-test and analysis of variance were used for the analysis of quantitative data. TSH and HOMA-IR were analysed after log transformation was performed. Spearman's rankrelated analysis and linear regression analysis were used to evaluate the correlation of the factors. Risk factors were analysed using logistic regression. Level of significance was set to $5 \%$.

\section{Ethical aspects}

Research protocols were approved by the medical ethics committee of The First Affiliated Hospital, China Medical University. All participants provided a written informed consent after the research protocols were carefully explained to them.

\section{Results}

The relationship between different serum TSH levels and mean blood pressure

The baseline characteristics of 1319 participants are shown in Table 1. After 115 patients who had taken hypotensive drugs in the past 4 weeks were excluded, using the Spearman's rank-related correlation analysis among the remaining 1204 persons, we found that the levels of serum TSH were not associated with either mean systolic blood pressure (SBP) or diastolic blood pressure (DBP) $(P>0.05)$, whereas age, gender, smoking status, HOMA-IR, BMI were associated with both SBP and DBP $(P=0.000)$. The multiple linear regression analysis showed that levels of serum TSH still had no relation with mean SBP and DBP, even after adjustment for above factors (Table 2).

The previous findings of our research group showed that the incidence of thyroid dysfunction between serum TSH level of 1.0 and $1.9 \mathrm{mIU} \mathrm{l}^{-1}$ was the lowest. ${ }^{9}$ There were 1226 participants whose serum TSH levels were within the reference range (0.3-4.8 $\mathrm{mIU} \mathrm{l}^{-1}$ ); after excluding 102 patients who had taken hypotensive drugs in past 4 weeks, the 
Table 1 Baseline characteristics of participants

\begin{tabular}{|c|c|c|c|}
\hline & All & Euthyroid & Subclinical hypothyroidism \\
\hline Number & 1319 & 1226 & 93 \\
\hline Age (year) & $44.8 \pm 13.5$ & $44.7 \pm 13.6$ & $46.2 \pm 12.8$ \\
\hline Gender (female \%) & $60.6 \%$ & $59.1 \%$ & $80.6 \%^{\mathrm{a}}$ \\
\hline Smoking status (smoking \%) & $23.8 \%$ & $25 \%$ & $7.5 \%^{\mathrm{a}}$ \\
\hline HBP (\%) & $32.8 \%$ & $32.3 \%$ & $39.8 \%$ \\
\hline SBP (mm Hg) & $126.9 \pm 21.1$ & $126.7 \pm 20.9$ & $130.2 \pm 23.9$ \\
\hline DBP (mm Hg) & $80.7 \pm 12.0$ & $80.7 \pm 11.9$ & $80.4 \pm 12.6$ \\
\hline TSH $\left(\mathrm{mIUl}^{-1}\right)$ & $2.3 \pm 1.7$ & $2.0 \pm 1.0$ & $6.8 \pm 2.4^{\mathrm{a}}$ \\
\hline BMI $\left(\mathrm{kg} \mathrm{m}^{-2}\right)$ & $24.3 \pm 3.7$ & $24.3 \pm 3.7$ & $24.4 \pm 3.2$ \\
\hline HOMA-IR & $2.8 \pm 5.1$ & $2.8 \pm 5.3$ & $2.4 \pm 1.2^{\mathrm{a}}$ \\
\hline
\end{tabular}

Abbreviations: BMI, body mass index; DBP, diastolic blood pressure; HOMA-IR, homoeostasis model assessment of insulin resistance; SBP, systolic blood pressure; TSH, thyroid-stimulating hormone.

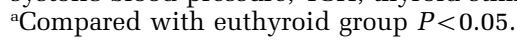

Table 2 Multiple linear regression analysis of the relationship between serum TSH and SBP and DBP

\begin{tabular}{|c|c|c|c|c|c|c|}
\hline & \multicolumn{3}{|c|}{$S B P$} & \multicolumn{3}{|c|}{$D B P$} \\
\hline & $B$ & s.e. & $\mathrm{P}$ & $B$ & s.e. & $\mathrm{P}$ \\
\hline Gender & -10.304 & 1.149 & $0.000^{*}$ & -6.605 & 0.724 & $0.000^{*}$ \\
\hline Age & 1.821 & 0.036 & $0.000^{*}$ & 0.109 & 0.023 & $0.000^{*}$ \\
\hline BMI & 0.295 & 0.141 & $0.000 *$ & 0.911 & 0.089 & $0.000^{*}$ \\
\hline Smoking status & -2.158 & 1.066 & $0.043^{*}$ & -1.324 & 0.672 & $0.049^{*}$ \\
\hline Lg(HOMA-IR) & 4.677 & 2.008 & $0.020^{*}$ & 4.280 & 1.266 & $0.001^{*}$ \\
\hline Lg(TSH) & 0.295 & 0.838 & 0.576 & 0.859 & 1.030 & 0.404 \\
\hline
\end{tabular}

Abbreviations: B, regression coefficient; BMI, body mass index; DBP, diastolic blood pressure; HOMA-IR, homoeostasis model assessment of insulin resistance; SBP, systolic blood pressure; s.e, standard error; TSH, thyroid-stimulating hormone.

${ }^{*} P<0.05$.

remaining 1124 individuals were divided into group A (TSH 0.3-0.99 $\mathrm{mIU} \mathrm{l}^{-1}, 211$ individuals), group B (TSH 1.0-1.9 $\mathrm{mIU}^{-1}, 430$ individuals) and group C (TSH 1.91-4.8 $\mathrm{mIU} \mathrm{l}^{-1}, 483$ individuals). Using variance analysis, both mean SBP and DBP were shown to be similar among three groups after adjusting for age, gender, smoking status, HOMAIR and BMI (Table 3).

\section{Influence of different serum TSH levels on hypertension prevalence}

Of the 1319 participants, 433 patients had hypertension and 886 didnot. The prevalence of hypertension in subclinical hypothyroidism group was significantly higher than that in euthyroid group in females ( 41.3 vs $25.6 \%, P<0.05$ ).

There were significant differences between hypertensives and non-hypertensives in age (52.2 \pm 12.4 vs $41.2 \pm 12.5$ years old), gender (female: 49.9 vs $68.5 \%)$, proportion of smokers (27.5 vs $22 \%)$, HOMA-IR $(3.0 \pm 1.5$ vs $2.4 \pm 1.2)$ and BMI (26.1 \pm 3.6 vs $23.4 \pm 3.4 \mathrm{~kg} \mathrm{~m}^{-2}$ ) (all $P<0.05$ ), which suggested that these factors were associated with hypertension. After adjusting for age, gender, smoking status, HOMA-IR and BMI, logistic regression analysis indicated that different serum TSH levels remained independent risk factors for hypertension (odds ratio $(\mathrm{OR})=1.324, \quad 95 \%$ CI $1.033-1.697$, $P=0.027$ ). The risk for hypertension in subclinical hypothyroidism group was 1.753 times more than that in euthyroid group (OR $=1.753$, 95\% CI $1.067-$ 2.879, $P=0.027$ ), this association was stronger in females $(\mathrm{OR}=3.545,95 \%$ CI 1.576-7.975, $P=0.004)$, but there was no significant difference in males (Table 4).

The prevalence of hypertension was similar among groups A, B and C in euthyroid participants. Logistic regression analysis showed that serum TSH levels in normal range were not associated with hypertension prevalence after adjusting for age, gender, smoking status, HOMA-IR and BMI $(\mathrm{OR}=0.990,95 \%$ CI $0.847-1.158, P=0.903)$.

\section{Discussion}

The cross-sectional epidemiological investigation indicated that there was no difference in mean blood pressure between the subclinical hypothyroidism group and euthyroid group. However, the prevalence of hypertension in subclinical hypothyroidism group was significantly higher than that in the euthyroid group. This association was especially stronger in females, and there was no statistical significance in males. 
Table 3 The comparisons of SBP and DBP among euthyroid participants

\begin{tabular}{lcccr}
\hline Group & TSH $\left(\mathrm{mIUl}^{-1}\right)$ & Number (individuals) & $S B P(\mathrm{~mm} \mathrm{Hg})$ & $D B P(\mathrm{~mm} \mathrm{Hg})$ \\
\hline A & $0.3-0.99$ & 211 & $124.7 \pm 19.0$ & $79.6 \pm 11.7$ \\
B & $1.0-1.9$ & 430 & $123.8 \pm 17.7$ & $81.0 \pm 11.8$ \\
C & $1.91-4.8$ & 483 & $123.9 \pm 19.2$ & $79.5 \pm 11.4$ \\
\hline
\end{tabular}

Abbreviations: BMI, body mass index; DBP, diastolic blood pressure; HOMA-IR, homoeostasis model assessment of insulin resistance; SBP, systolic blood pressure; TSH, thyroid-stimulating hormone.

Both SBP and DBP were adjusted for age, gender, smoking status, HOMA-IR and BMI.

Table 4 Comparison of risk for hypertension prevalence between different TSH level groups

\begin{tabular}{|c|c|c|c|c|c|c|}
\hline & $T S H\left(m I U l^{-1}\right)$ & $\mathrm{N}$ & Hypertensives (\%) & OR & $95 \% C I$ & $\mathrm{P}$ \\
\hline \multirow[t]{2}{*}{ All } & $0.3-4.8$ & 1226 & $396(32.3)$ & & & \\
\hline & $>4.8$ & 93 & 37 (39.8) & 1.753 & $1.067-2.879$ & $0.027^{*}$ \\
\hline \multirow[t]{2}{*}{ Male } & $0.3-4.8$ & 502 & $211(42.0)$ & & & \\
\hline & $>4.8$ & 18 & $6(33.3)$ & 0.776 & $0.255-2.361$ & 0.655 \\
\hline \multirow[t]{2}{*}{ Female } & $0.3-4.8$ & 724 & $185(25.6)$ & & & \\
\hline & $>4.8$ & 75 & $31(41.3)^{*}$ & 3.545 & $1.576-7.975$ & $0.004 *$ \\
\hline
\end{tabular}

Abbreviations: CI, confidence interval; OR, odds ratio; TSH, thyroid-stimulating hormone.

Compared with the participants with TSH between 0.3 and $4.8 \mathrm{mIU} \mathrm{l}^{-1},{ }^{*} P<0.05$.

Clinical hypothyroidism can raise the levels of blood pressure. The increment of systemic vascular resistance may be the main mechanism in clinical hypothyroidism patients. T3 can directly act on arterial smooth muscle cells of blood vessels to cause vasodilation. ${ }^{10}$ When hypothyroidism occurs, declining T3 level increases the vascular resistance and the level of blood pressure. Hypothyroidism can also lead to the abnormality of sodium metabolism, the sympathetic nervous system activity raising, and the glomerular filtration rate decreasing etc., which may be involved in the occurrence of hypertension. ${ }^{6,11,12}$ Blood pressure salt sensitivity was also one of the critical factors for hypertension in hypothyroid patients. ${ }^{13}$ The study of Gumieniak et al. ${ }^{6}$ showed that the relationship between FTI and salt sensitivity is, in part, mediated by the vascular action of thyroid hormone.

Recent researches indicated that cardiovascular disorders had existed in the subclinical hypothyroidism stage. Luboshitzky et al. ${ }^{3}$ found that the prevalence of hypertension in the subclinical hypothyroidism group was significantly higher than that in the normal control group, which coincided with our conclusion. Rotterdam's study showed that subclinical hypothyroidism was an independent risk factor for atherosclerosis and myocardial infarction. ${ }^{14}$ Blood hypercoagulability, blood viscosity increment, lipid abnormalities presenting in subclinical hypothyroidism patients could increase the risk for atherosclerosis, ${ }^{14}$ and these factors may also be involved in pathogenesis, in which the subclinical hypothyroidism affects the blood pressure.
Recently, the fact whether the reference range of serum TSH $\left(0.3-4.8 \mathrm{mIUl}^{-1}\right)$ is a safe range was doubted. When TSH was in the reference range, there was a linear increase in SBP and DBP with the increasing serum TSH levels, and the prevalence of hypertension also increased. ${ }^{5,14,15}$ The Whickham study indicated that serum TSH $2.0 \mathrm{mIUl}^{-1}$ was considered as the upper limit of the safe range. ${ }^{16}$ A prospective survey of our group found that the incidence of thyroid dysfunction between serum TSH level 1.0 and $1.9 \mathrm{mIU} \mathrm{l}^{-1}$ was the lowest. When the serum TSH level was $>1.9 \mathrm{mIUl}^{-1}$, the incidence of hypothyroidism increased, and when the serum TSH level $<1.0 \mathrm{mIUl}^{-1}$, the incidence of hyperthyroidism increased..$^{9}$ In present study, we divided the participants with euthyroidism into three groups according to the levels of serum TSH, that is, TSH $0.3-0.99,1.0-1.9$ and $1.91-4.8 \mathrm{mIU} \mathrm{l}^{-1}$, and the results showed that there were no association between the serum TSH level within the normal reference range with blood pressure. Roos et al. ${ }^{7}$ studied the association between euthyroidism and metabolic syndrome, they also did not find any relationship between serum TSH level and blood pressure. The serum TSH is the most sensitive indicator for the change of thyroid function, so in this study, we only analysed the association between the serum TSH levels and blood pressure.

In conclusion, our investigation confirmed that subclinical hypothyroidism could increase the risk for hypertension prevalence. More prospective studies should be performed to confirm the association between euthyroidism and blood pressure. TSH 
within the normal range was not associated with blood pressure.

What is known about topic?

- The prevalence of hypertension in subclinical hypothyroidism group was significantly higher than in euthyroid group in females.

- Change of TSH in normal range did not affect blood pressure.

What this study adds

- This epidemiological study explored the relationship between different levels of serum TSH and blood pressure in the participants with subclinical hypothyroidism and euthyroidism on the basis of cross-sectional epidemiological survey.

\section{Conflict of interest}

The authors declare no conflict of interest.

\section{Acknowledgements}

We express our gratitude to the staffs at the Health Bureau of Dadong District in Shenyang, Center for Chronic Disease Control, the Pearl of the Orient Community of Dadong District, the Yongfeng Community and the Dawn Community for their strong support and assistance to this epidemiological investigation. This study was supported by grants from the Chinese Medical Association (7020470055) and China Guanghua Science and Technology Foundation ([2007]02).

\section{References}

1 Cappola AR, Ladenson PW. Hypothyroidism and atherosclerosis. J Clin Endocrinol Metab 2003; 88: 2438-2444.

2 Prisant LM, Gujral JS, Mulloy AL. Hyperthyroidism: a secondary cause of isolated systolic hypertension. J Clin Hypertens (Greenwich) 2006; 8: 596-599.

3 Luboshitzky R, Aviv A, Herer P, Lavie L. Risk factors for cardiovascular disease in women with subclinical hypothyroidism. Thyroid 2002; 12: 421-425.

4 Hak AE, Visser TJ, Drexhage HA. Subclinical hypothyroidism is an independent risk factor for atherosclerosis and myocardial infarction in elderly women: The Rotterdam Study. Ann Intern Med 2002; 132: 270-278.

5 Asvold BO, Bjoro T, Nilsen TI, Vatten LJ. Association between blood pressure and serum thyroid-stimulating hormone concentration within the reference range: a population-based study. J Clin Endocrinol Metab 2007; 92: 841-845.

6 Gumieniak O, Perlstein TS, Hopkins PN, Brown NJ, Murphey LJ, Jeunemaitre X et al. Thyroid function and blood pressure homeostasis in euthyroid subjects. J Clin Endocrinol Metab 2004; 89: 3455-3461.

7 Roos A, Bakker SJ, Links TP, Gans RO, Wolffenbuttel $\mathrm{BH}$. Thyroid function is associated with components of the metabolic syndrome in euthyroid subjects. J Clin Endocrinol Metab 2007; 92: 491-496.

8 Hershman JM, Pekary AE, Berg L, Solomon DH, Sawin CT. Serum thyrotropin and thyroid hormone levels in elderly and middle-aged euthyroid persons. I Am Geriatr Soc 1993; 41: 823-828.

9 Teng W, Shan Z, Teng X, Guan H, Li Y, Teng D et al. Effect of iodine intake on thyroid diseases in China. $N$ Engl J Med 2006; 354: 2783-2793.

10 Ojamaa K, Klemperer JD, Klein I. Acute effects of thyroid hormone on vascular smooth muscle. Thyroid 1996; 85: 734-738.

11 Montenegro J, González O, Saracho R, Aguirre R, González O, Martínez I. Changes in renal function in primary hypothyroidism. Am J Kidney Dis 1996; 27: 195-198.

12 Myrup B, Bregengard C, Faber J. Primary haemostasis in thyroid disease. J Intern Med 1995; 238: 59-63.

13 Marcisz C, Jonderko G, Kucharz EJ. Influence of short-time application of a low sodium diet on blood pressure in patients with hyperthyroidism or hypothyroidism during therapy. Am J Hypertens 2001; 14: 995-1002.

14 Saltiki K, Voidonikola P, Stamatelopoulos K, Mantzou E, Papamichael C, Alevizaki M. Association of thyroid function with arterial pressure in normotensive and hypertensive euthyroid individuals: a cross-sectional study. Thyroid Res 2008; 29: 3-9.

15 Iqbal A, Figenschau Y, Jorde R. Blood pressure in relation to serum thyrotropin: the Tromsø study. J Hum Hypertens 2006; 20: 932-936.

16 Vanderpump MP, Tunbridge WM, French JM, Appleton D, Bates D, Clark F et al. The incidence of thyroid disorders in the community: a twenty-year follow-up of the Whickham Survey. Clin Endocrinol (Oxf) 1995; 43: $55-68$.

(c)

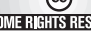

This work is licensed under the Creative Commons Attribution-NonCommercial-No Derivative Works 3.0 Licence. To view a copy of this licence, visit http://creativecommons.org/licenses/ by-nc-nd/3.0/ 